\title{
Sosialisasi Dan Pelatihan Penggunaan Internet Sehat Bagi Anggota Badan Usaha Milik Desa (Bumdes) Mozaik Desa Pematang Serai
}

\author{
Eko Hariyanto ${ }^{1}$ \\ Universitas Pembangunan Panca Budi, eko.hariyanto@dosen.pancabudi.ac.id \\ Sri Wahyuni ${ }^{2}$ \\ Universitas Pembangunan Panca Budi , sriwahyuni@dosen.pancabudi.ac.id
}

\begin{abstract}
Abstrak
Teknologi Internet dapat berakibat banyak hal negatif pada masyarakat jika tidak dibekali dengan pengetahuan. Di era globalisasi seperti sekarang ini internet menjadi kebutuhan utama dalam kehidupan sehari-hari. Internet memiliki peran yang sangat baik dalam membantu peran bisnis, pembelajaran, komunikasi maupun permaslaahan-permasalahan lain yang ditemukan saat tidak menggunakan internet atau biasa disebut cara manual. Jika tidak menggunakan dan mengikuti perkebangan internet maka akan tertinggal dari aspek bisnis dan ekonomi. Metode yang digunakan dalam pengabdian ini yaitu presentasi dan workshop secara langsung. Tujuan yang ingin dicapai dari pengabdian ini adalah meningkatkan pemahaman dan pengetahuan masyarakat khususnya Bumdes Mozaik Desa Pematang Serai mengenai penggunaan Internet yang aman, sehat dan tepat yang dapat meredam pengaruh buruk dari sisi dampak negatif yang ditimbulkan dari internet. Karena pada kenyataannya banyak masyarakat yang tidak memiliki pengetahuna tentang penggunaan internet yang sehat, aman dan tepat. Kemudian yang tak kalah penting adalah ketika penggunaan internet dilakukan secara sehat dengan penuh kesadaran maka akan meningkatkan kesejahteraan masyarakat khususnya Desa Pematang Serai. Hasil dari kegiatan pengabdian kepada masyarakat di Desa Pematang Serai yaitu peningkatan pemahaman dan pengetahuan peggunaan internet sehat.
\end{abstract}

Kata Kunci: Internet sehat, Globalisasi, Bumdes Mozaik

\section{Abstract}

Internet technology can have a lot of negative impact on society if it is not equipped with knowledge. In this era of globalization as today the Internet is the main need in everyday life. The internet has a very good role in assisting the role of business, learning, communication and other problems found when not using the Internet or commonly called the manual way. If not using and following the Internet Perkebangan then it will be left out of business and economic aspects. The methods used in this devotion are presentations and workshops directly. The purpose of this devotion is to improve the understanding and knowledge of the community, especially the Bumdes Mozaic village of Serai Pematang lemongrass about the safe, healthy and precise use of the Internet that can dampen the adverse effects of the negative impact of the Internet. Because in reality there are many people who do not have knowledge about healthy Internet use, safe and appropriate. Then what is not less important is when the Internet use is done healthily with full awareness it will improve the welfare of society, especially Pematang 
Serai village. The result of Community devotion activities in Desa Pematang Serai is increased understanding and knowledge of healthy Internet usage.

Keywords: Healthy Internet, Globalization, Mozilla Bumdes

\section{Pendahuluan}

Desa Pematang Serai adalah salah satu Desa yang terdapat di Tanjung Pura. Pada umumnya penduduk pematang serai bermata pencarian bertani berbagai jenis tanaman seperti padi, lada, jagung, pisang dan lain sebagainya, kemudian sebagaian lagi adalah peternak, seperti peternak ikan lele, jangkrik dan sapi. Desa Pematang Serai memiliki Bumdes Mozaik dimana bumdes tersebut mengelola Dana Desa dengan sangat baik sehingga meningkatkan kesejahteraan masyarakat di Desa Pematang Serai. BUMDes merupakan Lembaga usaha didesa dimana anggotanya terdiri dari masyarakat dan aparatur desa dengan tujuan memajukan ekonomi masyarakat desa sesuai dengan potensi dan kebutuhan dari des aitu senidiri, harapannya BUMDes memajukan unit usaha yang dijalankan masyarakat desa. (Ridzal and Hasan 2020). Namun anggota Bumdes masih memiliki pengetahuan yang minim tentang penggunaan internet yang sehat dan aman. Padahal tuntutan jaman yang semangkin canggih dan maju mengharuskan kita suka tidak suka dan mau ataupun tidak mau menggunakan internet dalam kehidupan sehari-hari. Bumdes sendiri memiliki peranan yang sangat penting dalam memajukan perekonomian masyarakat desa (Prasetyo 2017). Banyak upaya yang telah dilakukan oleh para peneliti dan dosen dalam melakukan pelatihan, workshop dalam memajukan Bumdes yang ada di Indonesia seperti pelatihan penyusunan laporan keuangan (Kusmayadi et al. 2019), pelatihan pemetaan potensi desa (Widiastuti, Kresnawati, and Rahman Utami 2019), pelatihan manajemen retail (Bagi, Mart, and Indonesia 2019), Pelatihan pemanfaatan media online (Radjab et al. 2017).

Internet sendiri sangat bermanfaat seperti dapat memasarkan produk hasil desa secara online (Wahyuni et al. 2019). Jika dapat menggunakan internet dengan tepat guna maka akan banyak manfaat yang dapat diperoleh masyarakat di Desa Pematang Serai. Penerapan internet khususnya pada smartphone atau perangkat elektronik lainnya yang semangkin memudahkan dalam hal komunikasi, pekerjaan dan pendidikan, bahkan ide atau inovasi yang dapat dilakuakan dalam mengembangkan Desa Pematang Serai menjadi lebih maju lagi, Namun, dalam penggunaan internet itu sendiri harus dibekali dengan pengetahuan dan penggunaan internet yang sehat dan aman. Pemahaman tentang penggunaan internet yang sehat sangat dibutuhkan oleh masyarakat desa (Winarso et al. 2017). Tak hanya para pelajar namun masyarakat desa juga harus di bekali dengan pengetahuan dan pemahaman internet yang sehat (Guntoro, Lisnawita, and Sadar 2019).

Permasalahan yang terjadi yaitu kurangnya pemahaman para anggota Bumdes BUMDES Mozaik tentang penggunaan internet yang aman dan sehat. Berikut ini akan di uraikan beberapa kelemahan dan permasalahan dari kurangnya pemahaman tentang penggunaan Internet Sehat bagi anggota Bumdes Mozaik di Desa Pematang Serai yang perlu diperhatikan: 
1. Penggunaan Teknologi yang semangkain meningkat.

Peningkatan penggunaan teknologi khusunya smartphone pada masyarakat yang tidak diimbangi dengan pengetahuan adanya dampak negatif dan positif dari penggunaan teknologi tersebut.

2. Kurangnya Penggunaan Teknologi khususnya smarthphone dengan sehat dan nyaman.

Hampir semua warga pematang serai mimiliki pengetahuan yang minim tentang bahaya internet dan kurangnya pengetahuan penggunaan internet yang sehat dan nyaman.

3. Kurangnya Pengetahuan tentang Penggunaan Internet yang sehat dan nyaman. Banyak masyarakat khusunya anggota Bumdes Pematang Serai yang tidak memahami bahaya penggunaan internet yang salah dan dapat memberi pengaruh buruk kepada masyarakat si pengguna itu sendiri.

\section{Metode}

Tim Pengabdian Kepada Masyarakat ( PKM ) yang terdiri dari 3 orang dosen dan 2 ornag mahasiswa Sistem Komputer. Mendapatkan ijin dari kepala Desa Pematang Serai melalui Direktur Bumdes Mozaik untuk menggunakan kantor Kepala Desa Pematang Serai sebagai tempat berkumpulnya anggota Bumdes Mozaik dan Tim dalam melakukan Pelatihan PKM Sosialisasi dan Pelatihan Penggunaan Internet Sehat Bagi Anggota Badan Usaha Milik Desa Mozaik. Tim melakukan Pendekatan dengan metode sosialisasi di awal dengan Ketua Bumdes Mozaik. Pelatihan dilakukan dengan Metode Ceramah dalam memperkenalkan Penggunaan Internet yang sehat dan aman, Para peserta di bekali dengan bahan ceramah berupa modul yang sudah Tim persiapkan PKM. Setelah materi ceramah di berikan dilanjutkan dengan diskusi tanya jawab agar tim memahami secara langsung permasalahan apa yang sering dihadapi oleh anggota BUMDES Mozaik ketika menggunakan internet agar materi praktek yang di berikan lebih tepat sasaran dan sesuai dengan kebutuhan masyarakat.

Dalam pelaksanaan Pelatihan Tim juga dibantu oleh dua orang mahasiswa dari program studi Sistem Komputer Universitas Pembangunan Panca Budi. Selesai Ceramah dilanjutkan dengan diskusi tanya jawab antara Anggota BUMDES mozaik dan tim, Kemudian sesi berikutnya dilakakuakn praktek secara langsung tentang penggunaan internet yang sehat dan aman, langsung di praktekan dengan smartphone dan laptop. Mahasiswa dilibatkan dalam membantu persiapan peralatan yang dibutuhkan pada saat pelatihan, sesi dokumentasi dan juga memandu para peserta pelatihan yang kurang paham dalam mengikuti pelatihan praktek secara langsung. Sesi praktek dilakukan Step by step agar diharapkan para peserta dapat dengan mudah menerima materi yang dipraktekan secara langsung oleh Tim PKM Universitas Pembangunan Panca Budi Medan. Setelah di lakukan Sesi praktek kemudian dibagikan kuisioner kepada para peserta untuk mengetahui sejauh mana penyerapan dan penerimaan materi yang telah di berikan oleh Tim PKM Universitas Pembangunan Panca Budi. 
Dalam memudahkan tim Melaksanakan PKM di desa Pematang Serai dengan lancar dan sukses maka tim melakukan Pemetaan dengan prosedur kerja. Adapaun prosedur kerja yang dilakukan oleh Tim adalah sebagai berikut :

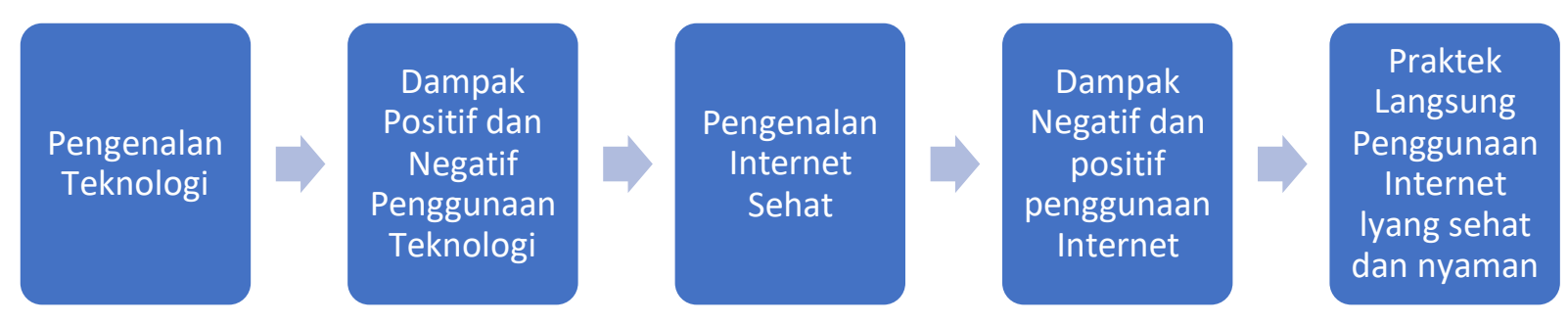

Gambar.1 Prosedur Kerja Tim Pengabdian Kepada Masyarakat

\section{Hasil dan Pembahasan}

Setelah dilaksanakan Pengabdian Kepada Masyarakat di Desa Pematang Serai khususnya kepada Anggota BUMDES Mozaik tentang penggunaan interenet yang sehat dan aman pada tanggal 6 November 2019 maka terjadi peningkatan pengetahuan dan keterampilan anggota Bumdes Mozaik, para peserta palatihan dan workshop yang terdiri dari para pengurus dan anggota BUMDes Mozaik sangat antusias dan bersemangat dalam mengikuti peatihan, target sasaran peserta pelatihan adalah BUMDES Mozaik dimana nanatinya anggota BUMDES Mozaik yang telah menerima pelatihan dapat menularkan pengetahuan dan keterampilannya kepada warga desa Pematang Serai lainnya. Sehingga masyarakat di pematang serai lainnya merasakan dampak adanya Pelatihan ini. Kendala yang dihadapi tim pada saat melaksanakn Pelatihan yaitu jarak tempuh antara Universitas Pembangunan Panca Budi dengan Kantor kepla Desa Pematang Serai (tempat dilakukannya Pelatihan) cukup jauh sehingga waktu dan memakan waktu dalam perjalanan yang mengurangi waktu pelatihan yang dilakukan, namu hal ini dapat di atasi dengan bantuan dari Universitas Pembangunan Panca Budi yang menyediakan tranportasi Bus Elf untuk keberangkatan Tim, untuk menyiasati waktu yang berkurang karena perjalanan yang jauh maka tim melakukan pendampingan secara berkala melalui Whatsap, Instagram dan komunikasi menggunakan Handphone agar permasalahan yang dihadapi tentang penggunaan Internet yang sehat dan aman dapat dibimbing oleh Tim PKM. 


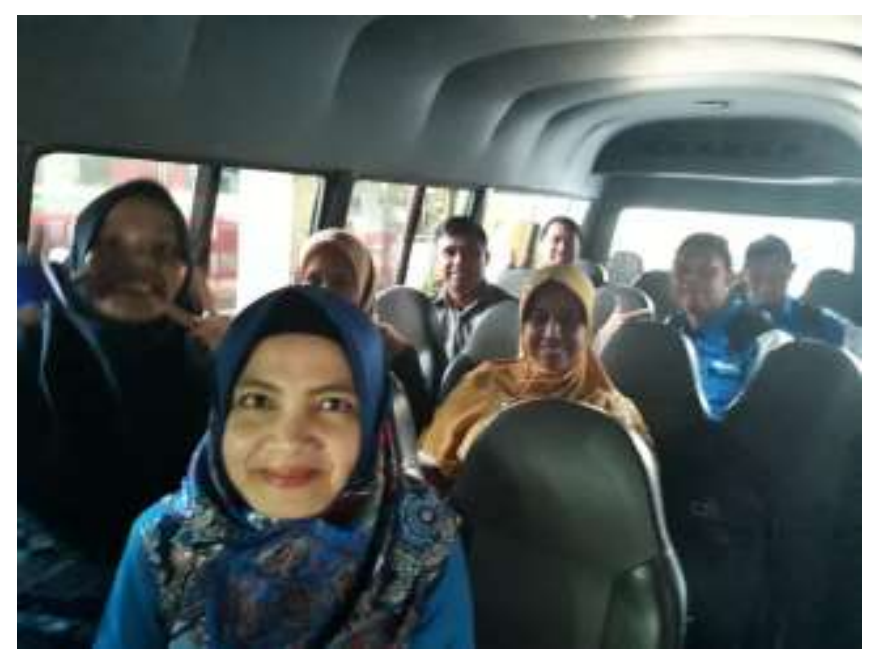

Gambar.2 Keberangkatan Tim PKM Menuju Desa Pematang Serai

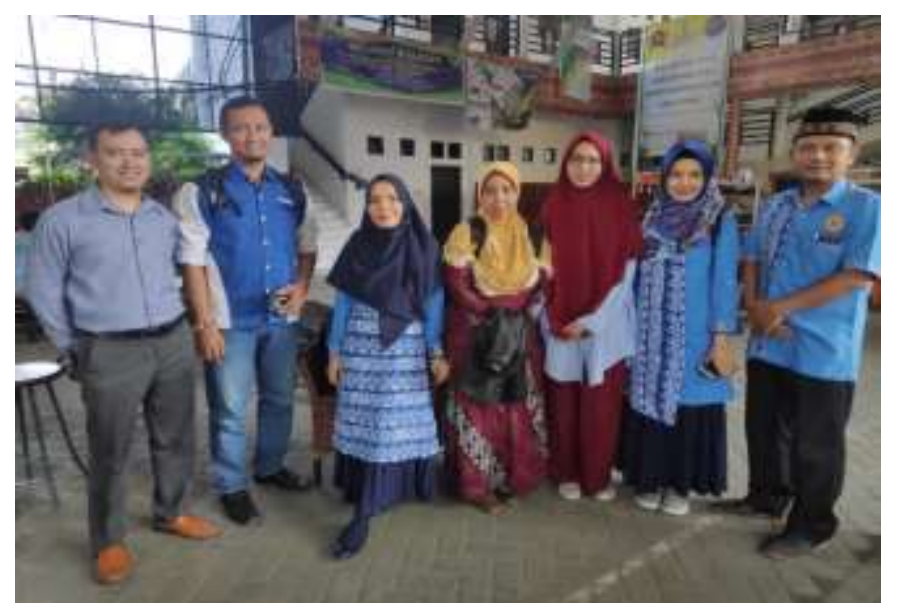

Gambar.3 Foto Tim PKM yang terdiri dari dosen dan mahasiswa UNPAB

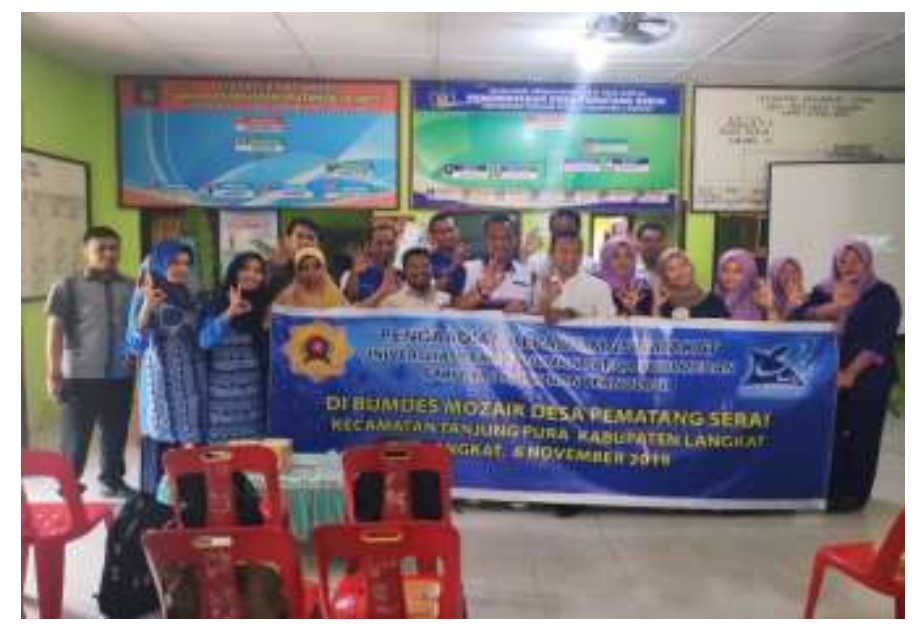

Gambar.4 Foto bersama Tim PKM dengan Anggota BUMDES Mozaik 


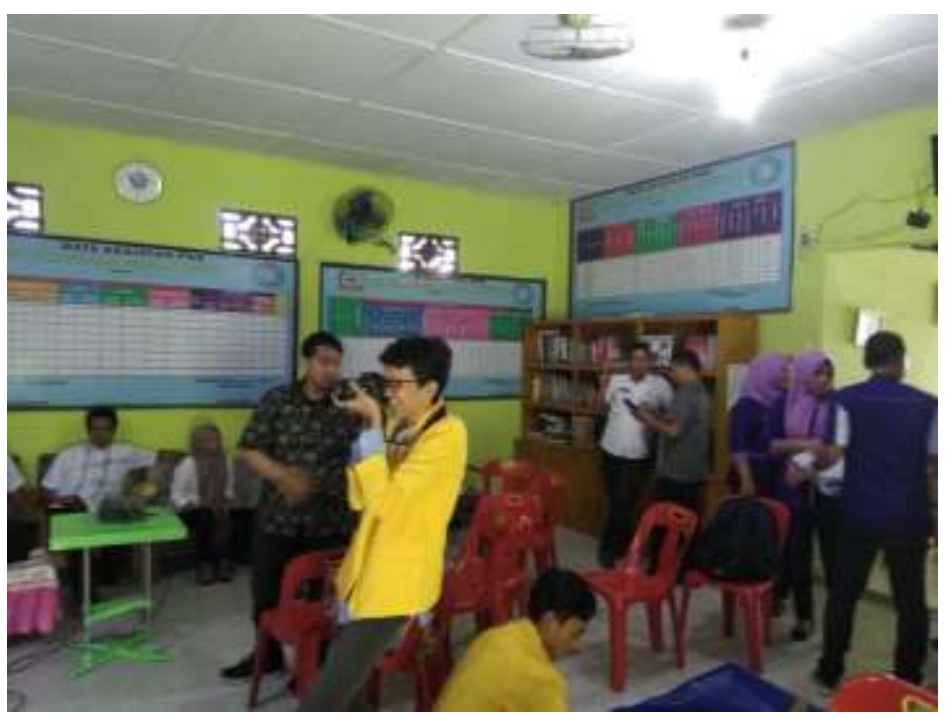

Gambar.5 Tim Dibantu oleh dua orang mahasiswa Sistem Komputer UNPAB

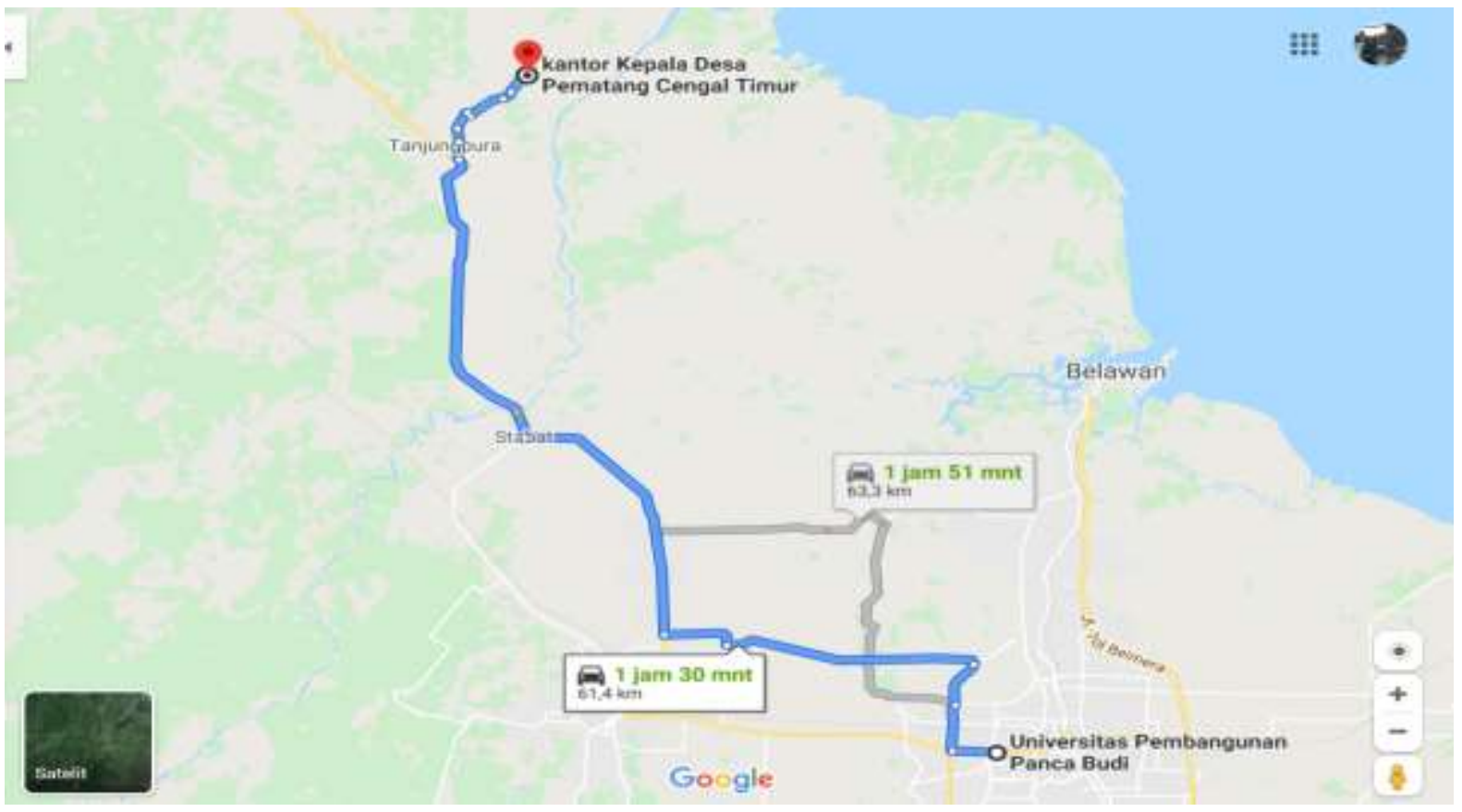

Gambar.6 Map jarak tempuh anatara UNPAB dan lokasi PKM

\section{Simpulan dan Rekomendasi}

Simpulan yang diperoleh adalah Pengabdian Kepada Mayarakat dengan judul Sosialisasi dan Pelatihan internet yang sehat dan Aman di Desa Pematang Serai Tanjung Pura kepada anggota BUMDES Mozaik berjalan lancar dan sukses. Terlihat dari peningkatan pengetahuan tentang internet yang sehat dan aman juga menngkat ini di tunjukan dari hasil kuisioner yang di berikan tim kepada para peserta yaitu anggota BUMDES Mozaik. 
Kesuskesan Tim PKM dalam melaksanakan sosialisasi dan pelatihan tak luput dari peran serta mitra yaitu direktur Bumdes dan para aoaratur desa pemantang serai yang banyak memberikan bantuan dan sangat baik dalam melakukan kerja sama.

Rekomendasi kegiatan selanjutnya disarankan melakukan pelatihan lebih dalam tentang internet dan penerapannya untuk usaha dan penjualanan produk hasil pertanian di Desa Pematang Serai

\section{Acknowledgements}

Kesuskesan Tim PKM dalam melaksanakan sosialisasi dan pelatihan tak luput dari peran serta Universitas Pembangunan Panca Budi dan LPPM UNPAB yang telah memberikan semua fasilitas yang dibutuhkan oleh Tim PKM dalam melaksanakan kegiatan baik dari segi perjalanan, administrasi dan lain sebagainya. Tak lupa yang paling penting yaitu direktur Bumdes dan para aparatur desa pemantang serai sebagai mitra yang banyak memberikan bantuan dan sangat baik dalam melakukan kerja sama.

\section{Daftar Pustaka}

Bagi, Fungsional, Bumdes Mart, and Di Indonesia. 2019. “Pelatihan Manajemen Ritail Berbasis Potensi Lokal Melalui Strategi." 1(1): 67-73.

Guntoro, Guntoro, Lisnawita Lisnawita, and Muhamad Sadar. 2019. "Pelatihan Internet Sehat Dan Aman Bagi Siswa SMK Masmur Pekanbaru." Jurnal Pengabdian Pada Masyarakat 4(2): 223-30.

Kusmayadi, Dedi, Irman Firmansyah, Rani Rahman, and Koperasi Nelayan. 2019. “IbBM PENYUSUNAN LAPORAN KEUANGAN BUMDES DAN KOPERASI NELAYAN DI of Financial Reports for BUMDES and Fisheries Cooperatives . Jurnal Pengabdian Siliwangi P-ISSN 2477-6629 E-ISSN 2615-4773." 5: 54-62.

Prasetyo, Ratna Azis. 2017. "Peranan Bumdes Dalam Pembangunan Dan Pemberdayaan Masyarakat Di Desa Pejambon Kecamatan ..." Jurnal Dialektika Volume XI(March 2016): 86-100.

Radjab, Enny et al. 2017. "Pelatihan Pemanfaatan Media Online Sebagai Sarana

Pemasaran." Prosiding Seminar Hasil Pengabdian Kepada Masyarakat (SNP2M) 2017: 292-95.

Ridzal, Nining Asniar, and Waode Adriani Hasan. 2020. “Eksistensi Badan Usaha Milik Desa (Bumdes) Sebagai Penggerak Ekonomi Desa." Jurnal Pengabdian Kepada Masyarakat MEMBANGUN NEGERI 4(1): 98-106.

Wahyuni, Sri, B Mesra, Akhyar Lubis, and Supina Batubara. 2019. “Penjualan Online Ikan Asin Sebagai Salah Satu Usaha Meningkatkan Pendapatan Masyarakat Nelayan Bagan Deli." 8(1): 89-94.

Widiastuti, Harjanti, Etik Kresnawati, and Evy Rahman Utami. 2019. "Pemetaan Potensi Desa Dalam Rangka Mewujudkan Bumdes Di Kecamatan Moyudan." BERDIKARI : Jurnal Inovasi dan Penerapan Ipteks 7(1): 1-13.

Winarso, Doni et al. 2017. "Pemanfaatan Internet Sehat Menuju Kehidupan

Berkemajuan." Jurnal Pengabdian UntukMu NegeRI 1(1): 19-23. 